\title{
Berit Callsen y Angelika Groß (Eds.). Cuerpos en oposición, cuerpos en composición: Representaciones de corporalidad en la literatura y cultura hispánicas actuales. Madrid/ Frankfurt am Main: Iberoamericana/ Vervuert, 2020, 223 páginas
}

Jorge Chen Sham

Chen Sham, J. (2021). Berit Callsen y Angelika Groß (Eds.). Cuerpos en oposición, cuerpos en composición: Representaciones de corporalidad en la literatura y cultura hispánicas actuales. Madrid/Frankfurt am Main: Iberoamericana/ Vervuert, 2020, 223 páginas. Revista de Filología y Lingüística de la Universidad de Costa Rica, 47(2), e46807. doi: https://doi.org/10.15517/rfl.v47i2.46807

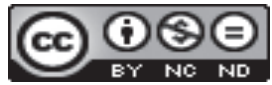

Doi: https://doi.org/10.15517/rfl.v47i2.46807

URL: https://revistas.ucr.ac.cr/index.php/filyling/index 
Revista de Filología y Lingüística de la Universidad de Costa Rica

ISSN: 0377-628X

ISSN: 2215-2628

filyling@gmail.com

Universidad de Costa Rica

Costa Rica

\title{
Berit Callsen y Angelika Groß (Eds.). Cuerpos en oposición, cuerpos en composición: Representaciones de corporalidad en la literatura y cultura hispánicas actuales. Madrid/Frankfurt am Main: Iberoamericana/ Vervuert, 2020, 223 páginas
}

\author{
Chen Sham, Jorge \\ Berit Callsen y Angelika Groß (Eds.). Cuerpos en oposición, cuerpos en composición: Representaciones de \\ corporalidad en la literatura y cultura hispánicas actuales. Madrid/Frankfurt am Main: Iberoamericana/ Vervuert, \\ 2020, 223 páginas \\ Revista de Filología y Lingüística de la Universidad de Costa Rica, vol. 47, núm. 2, e46807, 2021 \\ Universidad de Costa Rica, Costa Rica \\ Disponible en: http://www.redalyc.org/articulo.oa?id=33266553003 \\ DOI: https://doi.org/10.15517/rfl.v47i2.46807
}

\section{(C) $)(9 \Theta$}

Esta obra está bajo una Licencia Creative Commons Atribución-NoComercial-SinDerivar 3.0 Internacional. 
Berit Callsen y Angelika Groß (Eds.). Cuerpos en oposición, cuerpos en composición: Representaciones de corporalidad en la literatura y cultura hispánicas actuales. Madrid/ Frankfurt am Main: Iberoamericana/ Vervuert, 2020, 223 páginas

Jorge Chen Sham

Universidad de Costa Rica, San José, Costa Rica

jorgechsh@yahoo.com

(iD https://orcid.org/0000-0001-9692-4598
DOI: https://doi.org/10.15517/rfl.v47i2.46807

Redalyc: http://www.redalyc.org/articulo.oa?id=33266553003

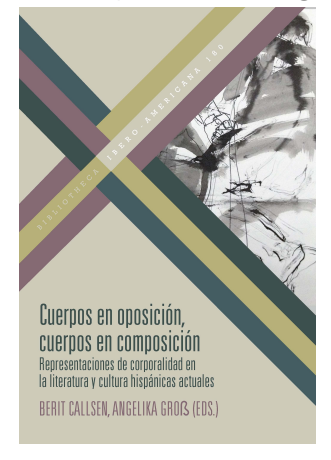

Callsen Berit, Groß Angelika. Cuerpos en oposición, cuerpos en composición: Representaciones de corporalidad en la literatura y cultura hispánicas actuales. 2020. Madrid/Frankfurt am Main. Iberoamericana/ Vervuert. 223pp.

El título del libro es de una gran pertinencia epistemológica, porque la noción del cuerpo, cuya extensión, significación y desplazamientos son más que actuales en el ámbito de las transgresiones y crisis de los tabúes que la constreñían, hace que sus definiciones salten para luego recomponerse con arreglo a prácticas artísticas y culturales propias del nuevo milenio. La propuesta de Callsen y Groß -secundada por los participantes de este volumen colectivo- es, en general, de grata lectura y permite dar un balance general a sus desafíos y desarrollos más recientes. El "Prefacio", muy breve, sirve apenas para esbozar unos planteamientos iniciales que grafican la intersección con campos como la discapacidad, la enfermedad, la violencia y el trauma, mientras que la preeminencia del cuerpo en la "constitución identitaria" (p. 9) es innegable para configurar un proceso de oposición/composición en torno a la representación y a los retos que el cuerpo dibuja y rediseña. Cuando se enfrenta a las dicotomías, activo/pasivo, desvío y norma, surge esa necesidad de abordar otros enfoques teórico-metodológicos que den cuenta del cuerpo desde otras estéticas y alcances éticos (p. 10), de modo que las editoras explican y reúnen los artículos en torno a secciones temáticas.

La sección "El cuerpo en la narrativa gráfica y las artes escénicas y visuales" (pp. 15-88) se presenta como la más novedosa desde la perspectiva de los estudios culturales. En “Tinta(s) femenina(s): la recuperación del cuerpo en la narrativa gráfica española y latinoamericana” (pp. 17-44), Jasmin Wrobel presenta un artículo novedoso al estudiar a las jóvenes dibujantes y el género de la "narrativa gráfica", cuyo elenco en el siglo XX ha sido marcado por la preeminencia masculina. En el nuevo milenio, Wrobel destaca el uso del medio gráfico dentro de una agenda política para "la negociación de discursos feministas" (p. 24) y pone los ejemplos de la colombo-ecuatoriana Powerpaola y su personaje femenino de Paola en Virus Tropical (2009) o de la venezolana-española Meritxell Bosch, en donde el giro autobiográfico es todo un reclamo en Yo, gorda (2017). La imagen corporal y la transgresión del cuerpo de la mujer se hacen ostensibles, al tiempo que aparece dentro del activismo gráfico, revistas como la argentina Clitoris (2011) o la chilena Brígida (2018), para concluir analizando esa tematización de los "nuevos" peligros que el cuerpo trans representa para la normatividad y el orden patriarcal, al poner el ejemplo de la brasileña Laerte Coutinho. Por su parte, en "Corporalidades 
especulativas: las mujeres-perro de Angélica Liddell y Paula Rego” (pp. 45-70), Mariana Simoni se centra en las metamorfosis de las "mujeres-perro" en tanto categorización de una hibridación distópica y descentradora. De las instalaciones y obras de la artista portuguesa Paula Rego, a la superposición de los cuerpos deformantes en la española Angélica Lidell, la performatividad y su fabulación especulativa apelan al efecto fantástico y de ciencia ficción, este último hoy involucra una reflexión sobre el entorno y, dentro de este, a los animales (p. 48), con el fin de buscar una mirada desde abajo. De esta manera, el sistema perceptivo se trastoca y se aborda el potencial difractivo de la escena (p. 52), que en Rego se aprecia en su "Tríptico del aborto", mientras en Lidell, en su sorprendente Perro muerto en tintorería (presentado en la temporada 2007-2008 en el Teatro Valle-Inclán de Madrid). Desde puntos de vista muy similares, Adrián Herrera-Fuentes analiza, en "Composición de la normatividad física u oposición a ella: sobre cuerpos extraordinarios en la cultura visual mexicana reciente" (pp.71-88), el cuestionamiento de las convenciones corporales al abordar la imperfección, la fealdad o la deformidad (p. 72) tanto en el pintor Arturo Rivera como en el ilustrador Alfredo Roagui. En Rivera, la deformidad se aprovecha de la ilusión realista lograda a través de una técnica fotográfica que pone en escena el dolor y la enfermedad, al tiempo que surge convocadas la discapacidad y la demencia (p. 73). Por su parte, Herrera-Fuentes insiste en la transgresión del atractivo físico y sus tecnologías (en el sentido foucauldiano) con "el cultivo de la estética corporal" (p. 80), para introducir una gráfica gay y de cultura popular, muy propia de las redes sociales. Los "hombres y personas transgénero" (p. 81), que dibuja Roagui con cuerpos atléticos, inciden en prácticas de socialización en donde el fisiculturismo se cotiza y se aprecia para mostrarse en el deseo homoerótico; lástima que Herrera-Fuentes no ilustró con ningún ejemplo sus comentarios.

La siguiente sección, "Imaginación, corporalidad y espacio" (pp. 89-171), constituye la parte central del libro y la de mayor desarrollo. Comienza con el trabajo de Lena Abraham con el título de "Del andrógino al siamés: mito, cuerpo y arquitectura en Laura y Julio (2006) de Juan José Millás” (pp. 91-107). La novela del español recurre al mito del andrógino y de los seres esféricos para plantear la naturaleza del amor y el castigo divino sobre la perfección física, lo cual da origen al deseo humano, con ese anhelo de la recuperación de la unidad perdida (p. 94) y la búsqueda del complemento de la media naranja que se dibuja, mental y arquitectónicamente hablando en la constitución del cuerpo-casa y del edificio en tanto unidad central del "ser humano" medida y centralidad según el Renacimiento, pues se descubre una simetría especular también con el departamento de su vecino y antagonista, Manuel. Por su parte, Berit Callsen nos ofrece en “Desdoblamientos y disidencias: cuerpo y doble en la obra de José María Merino y Guadalupe Nettel” (pp. 109-127), una de las propuestas más sólidas del volumen, cuando la temática del doble y sus irradiaciones sobre el cuerpo transparentan funciones metonímicas (indica Callsen, ahora bien desde nuestro punto de vista, serían más bien sinecdócticas) de duplicación, alteración, disidencia, desdoblamiento, las cuales catapultan "sensaciones de extrañeza y procesos de intrusión y dominación" (p. 109). Los casos del español Merino y de la mexicana Nettel le sirven a Callsen para subrayar los extrañamientos cuya experiencia se acentúa en "una separación del propio cuerpo" (p. 111) y "la disolución de una totalidad" (p. 126) muy propias de estas épocas de crisis y de fragmentariedad. El artículo de Minerva Peinador, "Lo que Hiper saca a flote: distopía de una Argentina líquida en La Plata postinundación, entre la autenticidad, la supervivencia y el delirio" (pp. 131-154), me desconcierta por su redacción en un género neutro (opta por la terminación -e) dentro de un trabajo de escritura académica y es que, como postura y activismo lo que explica Peinador en su nota de pie de página es válido, pero no en un libro como este. A pesar de lo anterior, su propuesta de cómo las inclemencias climatológicas con lluvias torrenciales se experimentan como una catástrofe en el marco de la conmemoración de Las Malvinas del año 2013, le permite plantear un miedo líquido que se pone en escena en las respuestas corporales a las crisis de la Argentina actual; pero cuando se trata de llevar esta idea a la interpretación de una biopolítica del desastre en la novela Hiper (2018) de Alejandro de Angelis, ella no ahonda en interpretaciones textuales. Para terminar esta sección, en "Cuerpos maricas, cuerpos travestis: cuerpo, performance y escritura en Pedro Lemebel” (pp. 155-171), Philipp Seidel aborda la figura 
iconoclasta del chileno, cuya obra rompe esas fronteras del arte visual y la literatura. Con esa constante puesta en movimiento que significa sus performances y la preeminencia del giro auto-mediático, tanto su etapa de activismo de izquierda como la de las "Yeguas del Apocalipsis" ofrecen una resistencia contestaria a partir de la readecuación de la figura de la "loca". Seidel insiste en que el deseo homoerótico y el activismo se reúnen en Lemebel y asume para sí la representación de la loca (p. 161); sin embargo, sus cuerpos extra/ordinarios (aludiendo a la exposición más importante sobre Lemebel en Chile) apenas se ejemplifican propiamente en los performances analizados por Seidel y de los cuales faltó, como todo performance, reproducir alguna muestra visual que acompañara sus explicaciones.

La última sección del libro, "Cuerpos en contextos violentos y dolorosos" (pp. 173-217), incluye tres artículos. En el primero, María Teresa Laorden Albendea se interesa por una novela centroamericana en "Con la posguerra en el cuerpo: transformaciones del saber y experiencia atravesada por la violencia en El ciclo dragón de Horacio Castellanos Moya" (pp. 175-188). Preocupada por la manera en que la violencia se ejerce sobre el cuerpo físico, la guerra y sus desastres afectan la carne y el alma (para volver a una expresión clásica) y se transparenta en el lenguaje y el proceso literario de quienes así lo abordan. La metáfora del estado putrefacto irradia sobre unos cuerpos mutilados, enfermos, desaparecidos o robotizados (p. 176), de modo que Laorden Albendea se interrogue sobre las representaciones que este provoca en tanto portador y transmisor de un saber. Este último desemboca en dos metáforas consecuentes, el "cuerpo instrumentalizado" y el "cuerpo enfermo", cuyas huellas en los personajes se ven como traumas en sus periplos y en sus vidas. Extraño, como en otros trabajos del volumen, que no se analice, primeramente y en forma "material o literal", las marcas corporales y sus afectaciones y contornos (desde lo físico y lo anímico hacia el exterior y sus irradiaciones metafóricas o sinecdóticas). En el segundo artículo, Angelika Groß se inclina por estudiar el caso deplorable del femicidio en México en "Cuerpos como objetos: violencia feminicida, deshumanización y objetivación de las víctimas" (pp. 189-203). La violencia del cuerpo produce una herida en la que esa dialéctica entre la víctima/victimario se problematiza en el acto de poder y de sumisión al que conlleva su mostración, para que el femicidio sea catalogado como el ejercicio de la dominación y del control sobre las mujeres (p. 191) y se estructure como una marca de la impunidad y de la inoperancia del Estado. Groß analiza particularmente el tratamiento de las muertas y desaparecidas en la novela de Bolaño 2666, en donde la violencia deshumanizada se vuelve "cuerpo" y "objeto" de la escritura policiaca en la sección medular "La parte de los crímenes". Termina el volumen el artículo de Diana Fuenmayor con el título de "La narración en segunda persona en Diario del dolor (2003) de María Luisa Puga: hacia una 'ontología del entre” (pp. 205-217), en donde la enfermedad y sus consecuencias le permite a la autora del artículo presentar el dolor y el malestar que acarrean las escisiones entre el sujeto y el objeto, de la voz narrativa y el cuerpo adolorido/enfermo, propiamente en la novela de la mexicana Puga. Una de las formas en que esta escisión se perfila discursivamente (y es un acierto de la novelista) es el desdoblamiento que la segunda persona permite, con el fin de que se ponga en escena una "ontología del entre" (p. 208). La noción de encrucijada desemboca aquí en una acentuación de "mi cuerpo", en ese momento en que se enuncia y habla la enfermedad para abolir, así, la continuidad y la unidad, que Puga lleva al terreno de la alteración temporal y la personificación del dolor (p. 210) de un cuerpo que quiere comunicar (p. 212) cuestionando el discurso médico, por ejemplo. 